\title{
Nature of Persecutors and Their Behaviors in the Delusions of Schizophrenia: Changes between the 1990s and the 2000s
}

\author{
Hyun Young $\mathrm{Oh}^{1}$, Daeho $\mathrm{Kim}^{1,2}$ and Yong-Chon Park ${ }^{1,2 \bowtie}$ \\ ${ }^{1}$ Department of Psychiatry, Hanyang University Medical Center, Seoul, Republic of Korea \\ ${ }^{2}$ Department of Psychiatry, College of Medicine, Hanyang University, Seoul, Republic of Korea
}

Objective Research suggests that the contents of delusions in schizophrenia are influenced by culture and social environment. However, few studies have investigated the chronological change of such delusions within a society. To investigate specifically the changes in the persecutory delusions of schizophrenia that have occurred over time, we compared the nature of the persecutors and their persecutory behaviors among inpatients with schizophrenia.

Methods All admissions to the psychiatric unit of Hanyang University Guri Hospital with discharge diagnoses of schizophrenia during two different five-year time frames (1996-2000 and 2006-2010) were reviewed. From their inpatient medical records, we investigated the descriptions of persecutors and their persecutory behaviors in the delusions of 124 patients (54 in the1990s and 72 in the 2000 s).

Results Overall, persecutory behaviors and nature of persecutors in the delusions of schizophrenia did not differ between the two time frames. However, subgroup analysis revealed that in women but not in men, rejection as a persecutory behavior was significantly higher in the 1990s $(\mathrm{p}<0.05)$.

Conclusion The ten-year time interval may be too short to find significant changes in delusional content in general. However, our additional finding in women may be a result of the tremendous change in status of Korean women during the last decade.

Psychiatry Investig 2012;9:319-324

Key Words Schizophrenia, Delusions, Culture, Cultural psychiatry, Symptoms.

\section{INTRODUCTION}

Schizophrenia is a chronic psychiatric illness characterized by psychotic symptoms such as delusions and hallucinations. ${ }^{1,2}$ It consistently affects about $1 \%$ of a population regardless of culture and ethnicity, although there exist minor differences among countries. ${ }^{3}$ This illness has a biogenetic basis, but interactions with the environment and culture are also considered influential, especially with respect to the symptoms manifested.,

Current literature indicates that the phenomenology of delusions and hallucinations in schizophrenia is influenced by the culture of the patient. ${ }^{6-12}$ Three major findings have emerged from previous studies: 1) the content and types of delusions

Received: April 26, 2012 Revised: June 23, 2012

Accepted: July 17, 2012 Available online: November 12, 2012

$\triangle$ Correspondence: Yong-Chon Park, MD, PhD

Department of Psychiatry, Hanyang University Guri Hospital, 153 Gyeongchunro, Guri 471-701, Republic of Korea

Tel: +82-31-560-2273, Fax: +82-31-554-2599, E-mail: hypyc@hanyang.ac.kr

(a) This is an Open Access article distributed under the terms of the Creative Commons Attribution Non-Commercial License (http://creativecommons.org/licenses/bync/3.0) which permits unrestricted non-commercial use, distribution, and reproduction in any medium, provided the original work is properly cited. and hallucinations differ among cultures ${ }^{8-12}$; 2) sociodemographic variables are associated with certain delusions and hallucinations ${ }^{13,14}$; 3) the content and frequency of delusions change over time within a given culture. ${ }^{15-17}$ Thus, the existing evidence consistently demonstrates that the delusions and hallucinations of schizophrenia reflect the societal status and cultural milieu of the patient.

Most studies in this area have examined the cross-cultural difference between western and eastern countries or among different ethnic groups within a nation. Relatively little attention has been paid to longitudinal changes in delusions within a culture. Klaf and Hamilton ${ }^{15}$ compared patients with schizophrenia from the 1850s and 1950s and found fewer religious delusions and more sexual delusions from the patients of 1950s. Additionally, Fujimori ${ }^{16}$ reported that Japanese patients with schizophrenia in 1965 displayed fewer delusions of grandiosity and possession and more delusions of persecution, reference, and illness than did patients 64 years previously. He suggested that this result reflected the transition of Japan to a society of nuclear families and industrialization, with more available information. Mitchell and Vierkant ${ }^{17}$ obtained similar 
findings in patients in a state hospital; the delusions of inpatients in the 1930s reflected the environment of the Great Depression, while the hallucinations of patients in the 1980s reflected dangerous sub-cultural milieus such as violence and perversion.

While these pioneering studies indicate that changes in the content of delusions and hallucinations tend to parallel societal and cultural changes, several methodological issues must be addressed before these findings can be generalized. For one, the studies assessed the content of delusions using different instruments so that results are difficult to consolidate meaningfully. They also examined a wide range of vaguely defined delusion types, rather than conducting a more focused investigation of a specific type of delusion. Further, in these studies, the time periods covered ranged from 50 to 100 years, which does not address short-term changes or more serial trends. One exception is a study by Uh and $\mathrm{Kim}^{18}$ that compared the persecutory delusions of schizophrenia between the 1980s and the 1990s. They found a decline in the number of political persecutors and an increase in the number of unidentified persecutors and a reduction in direct and violent persecutory behavior. These changes were in line with concurrent sociopolitical changes that took place in Korean society, and their study showed that even in a time from as short as a decade, changes in delusional content could be observed.

From the 1980s to the 1990s, South Korea underwent very rapid transformation from a traditional, politically oppressive and economically developing country to a westernized, individualistic, democratic society with economic wealth. This rapid evolution provides a good opportunity to study how such social changes may be reflected in the delusions of schizophrenia. ${ }^{18}$ In contrast, during the last decade, South Korean society has been politically and economically stable, motivating the current investigation of whether the changes that occurred in the decade before persisted during the last decade. This study is a continuation of a previous report on changes in persecutory delusion within the short time frame of a decade. Our study focused on persecutory delusion which is the most common type of delusion among patients with schizophrenia, across cultures. ${ }^{11,16,19}$ We examined the medical records of inpatients with schizophrenia at a university-affiliated hospital who were admitted during the 1990s and the 2000s.

\section{METHODS}

\section{Subjects}

All subjects in this study were inpatients in Hanyang University Guri Hospital, Gyeonggi, South Korea, who were discharged during the period from 1996 to 2000 or from 2006 to 2010. The medical records of patients with a discharge diagno- sis of schizophrenia based on ICD-10 were considered eligible for inclusion in the study. Exclusion criteria were mental retardation, neurological disorder, serious medical condition, and those with whose cultural background was not South Korean. Eight patients were admitted both in the 1990s and the 2000s were excluded. The medical charts of twenty four patients (19\%) in 1990s were lost and could not be accessed. Thus, the number of eligible patients was 104 in the 1990s and 143 in the 2000s. Of these participants, 69 (66\%) and 103 (72\%) respectively had persecutory delusions. Further, to rule out the possible effects of sustaining delusional content from the first to the second time frame, we exclude patients whose duration of illness (i.e., time passed after onset of positive symptoms such as delusion or hallucination) was more than five years. This created a final sample of 54 patients from the 1990s and 70 from the 2000s.

\section{Procedures}

After approval of the institution's research ethics review board was obtained for this study, each patient's records were evaluated by the first author using a checklist to categorize the delusions. The checklist contained a classification of persecutors developed by Uh and $\mathrm{Kim}^{18}$ and persecutory behaviors based on a classification of aggressive social interactions originally developed as part of a dream coding system. ${ }^{20}$

Types of persecutors on the checklist included political figures (police, secret service agents, military or communist party leaders), family and relatives, coworkers or friends, neighbors, unidentified persons, supernatural beings and religious leaders, millionaires, medical personnel, teachers, creditors, and members of the communist army. ${ }^{18}$ Categories and examples of persecutory behaviors on the checklist included murder (A8: death), physical attack (A7: attempt at physical harm such as personal assault or using a weapon), chasing or capturing (A6: including confining or physically coercing), theft or destruction of possession (A5: destruction of property), serious verbal threat (A4: serious accusation or verbal threat of harm), rejection or refusal (A3: including exploitation, control, or verbal coercion), critical remark (A2: yelling, swearing, or criticizing), and angry thoughts (A1: covert feeling of hostility or anger without overt expression).$^{20}$

To measure inter-rater reliability of the checklist, the first and second author each completed the checklist for a non-random sample of 30 participants' records. The kappa when comparing the ratings for persecutory behaviors and the nature of persecutors were 0.67 and 0.91 , respectively.

\section{Analysis}

For all the categorical variables that included persecutors and persecutory behaviors, we used the Chi-square test or 
Fisher's exact test to compare the distributions for the two time-periods. For the continuous variables that were not normally distributed, the Mann Whitney test was conducted to compare between groups. All the data were analyzed with SPSS for Windows Version 18 and statistical significance was set at the level of 0.05 bidirectionally.

\section{RESULTS}

\section{Baseline characteristics}

Compared with patients in the 1990s, those in the 2000s were significantly older [mean 33.1 ( $\mathrm{SD}=8.1)$ vs. 28.3 ( $\mathrm{SD}=$ 11.2), $\mathrm{p}=0.017$ ]. Table 1 shows the sociodemographic characteristics: significantly more females were observed in the pa- tients from the 2000s (69\% vs. 46\%, p<0.05), while other variables (marital status, education, employment, household income, and previous psychiatric admissions) did not differ between two groups. There were also no statistical differences in the duration of illness, the number of previous hospitalization, and hospital days of the index admission (Table 1). With binary logistic regression analysis, we confirmed that the difference in age of the two groups did not affect the distribution of types of persecutors.

\section{Persecutory delusions}

Overall, the most common persecutory behaviors in the two groups were chasing or capturing (33\%), angry thoughts (27\%), physical attack (26\%), critical remark (20\%), and mur-

Table 1. Baseline characteristics of participants with schizophrenia in the 1990s and 2000s $(N=124)$

\begin{tabular}{|c|c|c|c|c|}
\hline & $1990 \mathrm{~s}(\mathrm{~N}=54)$ & $2000 \mathrm{~s}(\mathrm{~N}=70)$ & Statistics & nvelup \\
\hline & Mean (SD) & Mean (SD) & $\mathrm{U}^{*}$ & Pratur \\
\hline Age & $28.3(8.1)$ & $33.1(11.2)$ & 2362.0 & 0.017 \\
\hline Duration of illness (months) & $17.0(16.4)$ & $20.4(17.9)$ & 2138.5 & 0.209 \\
\hline \multirow[t]{2}{*}{ Hospital days } & $48.0(30.1)$ & $53.2(32.1)$ & 2053.5 & 0.410 \\
\hline & $\mathrm{N}(\%)$ & $\mathrm{N}(\%)$ & $\chi^{2}$ & \\
\hline \multicolumn{5}{|l|}{ Sex } \\
\hline Male & $29(53.7)$ & $22(31.4)$ & 6.3 & 0.012 \\
\hline Female & $25(46.3)$ & $48(68.6)$ & & \\
\hline \multicolumn{5}{|l|}{ Marital status } \\
\hline Married & $13(24.1)$ & $24(34.3)$ & 3.4 & 0.337 \\
\hline Divorced & $4(7.4)$ & $2(2.9)$ & & \\
\hline Widowed & 0 & $1(1.4)$ & & \\
\hline Never married & $37(68.5)$ & $43(61.4)$ & & \\
\hline \multicolumn{5}{|l|}{ Education } \\
\hline Less than high school & $17(31.5)$ & $15(21.4)$ & 2.9 & 0.229 \\
\hline High school graduate & $33(61.1)$ & $44(62.9)$ & & \\
\hline University graduate & $4(7.4)$ & $11(15.7)$ & & \\
\hline \multicolumn{5}{|l|}{ Employment } \\
\hline Unemployed & $21(38.9)$ & $31(44.3)$ & 1.3 & 0.736 \\
\hline Employed & $12(22.2)$ & $16(22.9)$ & & \\
\hline Student & $9(16.7)$ & $7(10.0)$ & & \\
\hline Housewife & $12(22.2)$ & $16(22.9)$ & & \\
\hline \multicolumn{5}{|l|}{ Monthly income ${ }^{\dagger}$} \\
\hline Less than 2000 & $25(46.3)$ & $20(28.6)$ & 6.0 & 0.113 \\
\hline 2000-3999 & $23(42.7)$ & $39(55.7)$ & & \\
\hline $4000-5999$ & $5(9.3)$ & $11(15.7)$ & & \\
\hline More than 6000 & $1(1.9)$ & 0 & & \\
\hline \multicolumn{5}{|l|}{ Previous admissions } \\
\hline None & $38(70.4)$ & $52(74.3)$ & 0.3 & 0.862 \\
\hline One & $13(24.1)$ & $14(20.0)$ & & \\
\hline Two to four & $3(5.6)$ & $4(5.7)$ & & \\
\hline
\end{tabular}

*Mann-Whitney U, thousehold income in US dollars 
der $(18 \%)$. The most commonly described persecutors were unidentified persons (69\%), followed by family or relatives (17\%), coworkers or friends (14\%), and neighbors (14\%). No cases described a persecutor in the category of creditor.

Our analysis indicated that there were no significant differences in persecutory behaviors or persecutors in the records of the patients in the 1990s and 2000s, when taken as a whole (Table 2 and 3). In women, however, rejection or refusal was significantly more frequent in the 1990s [3 (12.0\%) vs. 0, p< $0.05]$. In fact, all three of these cases involved persecutory delusions that the patient's family was shunning, ignoring, or distancing her. One believed that her husband was trying to divorce her and had plotted this with her own parents. A second reported that her family tried to throw her out from the house despite the fact that she was economically dependent. And the third patient professed that her family ignored her and left her out because she did not go to college while her brothers were college educated.

\section{DISCUSSION}

The main finding in this study was that rejection or refusal was the only significantly different category of persecutory behaviors between the delusions of schizophrenic patients of the 1990s and 2000s. This finding was seen in women but not in men. Furthermore, no case reported rejection or refusal as a persecutory behavior in the 2000s. Similarly, a decrease in frequency of rejection or refusal was noted in a previous study by Uh and Kim, ${ }^{18}$ who compared patients with schizophrenia between the 1980s and 1990s. Their study was conducted at a different center, but since we used the same instruments, our results can be considered to be an extension of their findings. Unfortunately, they did not report subgroup analysis between sexes, and therefore, it is uncertain whether the observed ch-

Table 2. Persecutory behaviors in delusions of schizophrenia in the 1990s and 2000s

\begin{tabular}{|c|c|c|c|c|c|c|c|c|c|}
\hline & \multicolumn{2}{|c|}{ Total $(\mathrm{N}=124)$} & \multirow[b]{2}{*}{$\mathrm{p}$} & \multicolumn{2}{|c|}{$\operatorname{Men}(\mathrm{N}=51)$} & \multirow[b]{2}{*}{$\mathrm{p}$} & \multicolumn{2}{|c|}{ Women $(\mathrm{N}=73)$} & \multirow[b]{2}{*}{$\mathrm{p}$} \\
\hline & $\begin{array}{c}1990 \mathrm{~s} \\
(\mathrm{~N}=54)\end{array}$ & $\begin{array}{c}2000 \mathrm{~s} \\
(\mathrm{~N}=70)\end{array}$ & & $\begin{array}{c}1990 \mathrm{~s} \\
(\mathrm{~N}=29)\end{array}$ & $\begin{array}{c}2000 \mathrm{~s} \\
(\mathrm{~N}=22)\end{array}$ & & $\begin{array}{c}1990 \mathrm{~s} \\
(\mathrm{~N}=25)\end{array}$ & $\begin{array}{c}2000 \mathrm{~s} \\
(\mathrm{~N}=48)\end{array}$ & \\
\hline Murder & $7(13.0)$ & $15(21.4)$ & 0.221 & $3(10.3)$ & $3(13.6)$ & $1.000^{*}$ & $4(16.0)$ & $12(25.0)$ & 0.378 \\
\hline Physical attack & $12(22.2)$ & $20(28.6)$ & 0.423 & $7(24.1)$ & $3(13.6)$ & $0.483^{*}$ & $5(20.0)$ & $17(35.4)$ & 0.173 \\
\hline Chasing-capturing & $17(31.5)$ & $24(34.3)$ & 0.742 & $9(31.0)$ & $8(36.4)$ & 0.689 & $8(32.0)$ & $16(33.3)$ & 0.908 \\
\hline Theft or destruction & 0 & $2(2.9)$ & $0.504^{*}$ & 0 & 0 & & 0 & $2(4.2)$ & $0.543^{*}$ \\
\hline Serious threat & $1(1.9)$ & $2(2.9)$ & $1.000^{*}$ & 0 & 0 & & $1(4.0)$ & $2(4.2)$ & $1.000^{*}$ \\
\hline Rejection or refusal & $3(5.6)$ & 0 & 0.080 & 0 & 0 & & $3(12.0)$ & 0 & $0.037^{*}$ \\
\hline Critical remark & $10(18.5)$ & $15(21.4)$ & 0.822 & $5(17.2)$ & $7(31.8)$ & 0.224 & $5(20.0)$ & $8(16.7)$ & $0.754^{*}$ \\
\hline Angry thoughts & $15(27.8)$ & $18(25.7)$ & 0.797 & $9(31.0)$ & $7(31.8)$ & 0.952 & $6(24.0)$ & $11(22.9)$ & 0.917 \\
\hline Others & $1(1.9)$ & $5(7.1)$ & 0.231 & $1(3.4)$ & $3(13.6)$ & 0.303 & 0 & $2(4.2)$ & 0.543 \\
\hline
\end{tabular}

Statistical analysis used either Chi-square or Fisher's exact test. *by Fisher's exact test

Table 3. Nature of persecutors in delusions of schizophrenia in the 1990s and 2000s

\begin{tabular}{|c|c|c|c|c|c|c|c|c|c|}
\hline & \multicolumn{2}{|c|}{ Total $(\mathrm{N}=124)$} & \multirow[b]{2}{*}{$\mathrm{p}$} & \multicolumn{2}{|c|}{$\operatorname{Men}(\mathrm{N}=51)$} & \multirow[b]{2}{*}{$\mathrm{p}$} & \multicolumn{2}{|c|}{ Women $(\mathrm{N}=73)$} & \multirow[b]{2}{*}{$\mathrm{p}$} \\
\hline & $\begin{array}{c}1990 \mathrm{~s} \\
(\mathrm{~N}=54)\end{array}$ & $\begin{array}{c}2000 \mathrm{~s} \\
(\mathrm{~N}=70)\end{array}$ & & $\begin{array}{c}1990 s \\
(\mathrm{~N}=29)\end{array}$ & $\begin{array}{c}2000 s \\
(\mathrm{~N}=22)\end{array}$ & & $\begin{array}{c}1990 \mathrm{~s} \\
(\mathrm{~N}=25)\end{array}$ & $\begin{array}{c}2000 \mathrm{~s} \\
(\mathrm{~N}=48)\end{array}$ & \\
\hline Political figures & $3(5.6)$ & $4(5.7)$ & $0.970^{*}$ & $2(6.9)$ & $2(9.1)$ & $1.000^{*}$ & $1(4.0)$ & $2(4.2)$ & $1.000^{*}$ \\
\hline Family or relatives & $9(16.7)$ & $12(17.1)$ & 0.674 & $4(13.8)$ & $1(4.5)$ & $0.375^{*}$ & $5(20.0)$ & $11(22.9)$ & 0.762 \\
\hline Coworkers or friends & $6(11.1)$ & $11(15.7)$ & 0.460 & $5(17.2)$ & $2(9.1)$ & $0.684^{*}$ & $1(4.0)$ & $9(18.8)$ & $0.149^{*}$ \\
\hline Neighbors & $9(16.7)$ & $8(11.4)$ & 0.500 & $4(13.8)$ & $2(9.1)$ & $0.688^{*}$ & $5(20.0)$ & $6(12.5)$ & $0.494^{*}$ \\
\hline Unidentified & $28(51.9)$ & $46(65.7)$ & 0.119 & $12(41.4)$ & $14(63.6)$ & 0.115 & $16(64.0)$ & $21(66.7)$ & 0.820 \\
\hline Religious figures & 0 & $3(4.3)$ & $0.356^{*}$ & 0 & $1(4.5)$ & $0.431^{*}$ & 0 & $2(4.2)$ & $0.543^{*}$ \\
\hline The rich & 0 & $1(1.4)$ & $1.000^{*}$ & 0 & 0 & & 0 & $1(2.1)$ & $1.000^{*}$ \\
\hline Medical personnel & 0 & $1(1.4)$ & $1.000^{*}$ & 0 & 0 & & 0 & $1(2.1)$ & $1.000^{*}$ \\
\hline Teacher & 0 & $1(1.4)$ & $1.000^{*}$ & 0 & 0 & & 0 & $1(2.1)$ & $1.000^{*}$ \\
\hline Red army & $1(1.9)$ & 0 & $0.435^{*}$ & $1(3.4)$ & 0 & $1.000^{*}$ & 0 & 0 & \\
\hline Others & $3(5.6)$ & $3(4.3)$ & $1.000^{*}$ & $2(6.9)$ & $2(9.1)$ & $1.000^{*}$ & $1(4.0)$ & $1(4.0)$ & $1.000^{*}$ \\
\hline
\end{tabular}

Statistical analysis used either Chi-square or Fisher's exact test. *by Fisher's exact test 
ange was also more robust in women in their study.

A great improvement in the social status of women with movement toward equality for the sexes has been occurring since the early 1990s. ${ }^{21}$ Women are more active in labor and social activities; they are more independent economically and emotionally from their husbands. ${ }^{21}$ Among with these changes, the divorce rate has risen steeply since the late 1990s. ${ }^{22}$ Thus, the rejecting or refusing themes seen among some women in the 1990s of the threat of divorce, leaving home, and women's lower educational attainment as may no longer make sense in the 2000s as an act of persecution in individuals' belief systems.

Uh and $\mathrm{Kim}^{18}$ found that milder forms of persecutory behaviors (verbal threat) were more frequent in the 1990s than the 1980s, while more severe behaviors (destruction of possessions, serious threat) were less frequent. We did not observe this pattern when comparing the 1990s and 2000s. This is probably due to the relatively stable sociopolitical environment in the late 1990s and 2000s. Both studies used the time interval of ten years; however, the particular intervals made profoundly different meanings for South Koreans due to the rapid political and cultural changes of the mid 1980s compared to the relatively stable social atmosphere of the 1990s. ${ }^{23}$

Moreover, this view is supported by our finding that only about $5 \%$ of patients reported political persecutors in our groups. This percentage was $28 \%$ in the early 1980 s and $12 \%$ in the early 1990 s, in a previous study. ${ }^{18}$ Thus, the decrease in political persecutors in schizophrenic delusions during the late 1990s and 2000s appears to parallel the decrease of political threats in real life. In the mid-1980s, South Korea was under a military dictatorship; the antigovernment movement was brutally oppressed and met with coercive persecution. ${ }^{24}$ Even non-activist people had to endure a high level of surveillance from police, secret service agents and the military. However, in 1987, a national election produced a non-military regime and initiated democratization. Thus, in the 2000s, the nation became one of the few free, democratic societies in Asia. ${ }^{25}$

Studies from politically stable, developed countries such as England, America, and Japan have compared time frames of 50 to 100 years, in order to find changes in delusional content. ${ }^{15-17}$ This may indicate that as a society develops into a more static and stable system, more time seems to be needed for enough social changes to occur or it to be reflected in the minds and belief systems of schizophrenia.

To our knowledge, no other study has examined chronological changes in schizophrenic delusions of persecution; however, our findings are consistent with other studies that have found that sociopolitical changes seem to affect delusional themes. For example, Skodlar et al. ${ }^{26}$ showed that persecutory and referential delusions increased after regime change in Slovenia. In a review, Sher ${ }^{27}$ has also argued that sociopolitical events affect the contents of delusions in psychotic disorders.

Collectively, the findings of the current and earlier studies show that sociocultural changes in the environment seem to affect how patients with schizophrenia perceive their external world, which in turn influences how they interpret their inner psychotic experiences.

There were several limitations of this study. First, it was based on data from retrospective chart reviews, and future research may benefit from the development of an interview instrument to better assess the content of persecutory delusions. Second, the coding system used for persecutory behaviors was originally developed for dream analysis. Although we believe these categories fit well to persecution content, validity has not been examined for this application. Third, patients in this study were acute inpatients in a tertiary referral center, thus limiting generalization to more chronic populations. An outpatient sample may have been more diverse and representative, but a concern exists for the quality and quantity of information in their charts. Fourth, the sample sizes for the variables with lower frequencies in the subgroup analysis were often too small. For example, "rejection or refusal" had a statistical significant result, but with only three cases in the category it cannot be seen as clinically meaningful.

Despite these limitations, our study is one of only a few that have examined changes with time in the delusional content of schizophrenia. Our study provided support to the theory that the culture and expectations in a society influence the nature of the delusions that are formed and maintained in it. ${ }^{29}$ Understanding the psychosocial meaning of specific delusions in patients with psychosis is an interesting topic for cultural psychiatrists, as well as being clinically significant for clinicians working with this population.

In conclusion, we found that the a specific type of content in the delusions of patients with schizophrenia, i.e., persecutors and their behaviors, changes in accordance with societal transformation, supporting the view that delusional content of schizophrenia reflects the sociocultural characteristics of the time. With this implication in mind, clinicians can better understand the meaning of psychotic symptoms in schizophrenia, which can help them to facilitate engagement and patient cooperation when dealing with delusions in therapy.

\section{REFERENCES}

1. American Psychiatric Association. Diagnostic and Statistical Manual of Mental Disorders, Fourth Edition. Washington DC: American Psychiatric Press; 1994.

2. World Health Organization. International Statistical Classification of Disease and Related Health Problems, 10th Revision. Geneva: WHO; 1992.

3. World Health Organization. The International Pilot Study of Schizophrenia. Geneva: WHO; 1973.

4. Murphy HB, Wittkower ED, Fried J, Ellenberger H. A cross-cultural 
study of schizophrenic symptomatology. Int J Soc Psychiatry 1963;9: 237-249.

5. Ndetei DM. Psychiatric phenomenology across countries: constitutional, cultural, or environmental? Acta Psychiatr Scand Suppl 1988;344: 33-44.

6. Suhail K, Cochrane R. Effect of culture and environment on the phenomenology of delusions and hallucinations. Int J Soc Psychiatry 2002; 48:126-138.

7. Thomas P, Mathur P, Gottesman II, Nagpal R, Nimgaonkar VL, Deshpande SN. Correlates of hallucinations in schizophrenia: a cross-cultural evaluation. Schizophr Res 2007;92:41-49.

8. Azhar MZ, Varma SL, Hakim HR. Phenomenological differences of delusions between schizophrenic patients of two cultures of Malaysia. Singapore Med J 1995;36:273-275.

9. Weisman AG, López SR, Ventura J, Nuechterlein KH, Goldstein MJ, Hwang S. A comparison of psychiatric symptoms between Anglo-Americans and Mexican-Americans with schizophrenia. Schizophr Bull 2000; 26:817-824.

10. Ensink K, Robertson BA, Ben-Arie O, Hodson P, Tredoux C. Experssion of schizophrenia in black Xhosa-speaking and white English-speaking South Africans. S A fr Med J 1998;88:883-887.

11. Kim KI, Li D, Jiang Z, Cui X, Lin L, Kang JJ, et al. Schizophrenic delusions among Koreans, Korean-Chinese and Chinese: a transcultural study. Int J Soc Psychiatry 1993;39:190-199.

12. Kim K, Hwu H, Zhang LD, Lu MK, Park KK, Hwang TJ, et al. Schizophrenic delusions in Seoul, Shanghai and Taipei: a transcultural study. J Korean Med Sci 2001;16:88-94.

13. Rudaleviciene P, Adomaitiene V, Stompe T, Narbekovas A, Meilius K, Raskauskiene N, et al. Delusions of persecution and poisoning in patients with schizophrenia: sociocultural and religious background. Medicina (Kaunas) 2010;46:185-192.

14. Lucas CJ, Sainsbury P, Collins JG. A social and clinical study of delusions in schizophrenia. J Ment Sci 1962;108:747-758.

15. Klaf FS, Hamilton JG. Schizophrenia--a hundred years ago and today. J Ment Sci 1961;107:819-827.

16. Fujimori H. Chronological changes in the subjects of delusion in schizo- phrenia. Seishin Shinkeigaku Zasshi 1978;80:669-703.

17. Mitchell J, Vierkant AD. Delusions and hallucinations as a reflection of the subcultural milieu among psychotic patients of the 1930s and 1980s. J Psyhol 1989;123:269-274.

18. Uh HG, Kim KI. Chronological change of persecutors in schizophrenic delusion: comparison between 1980-1982 and 1990-1992. J Korean Neuropsychiatr Assoc 1993;32:195-201.

19. Tateyama M, Asai M, Kamisada M, Hashimoto M, Bartels M, Heimann H. Comparison of schizophrenic delusions between Japan and Germany. Psychopathology 1993;26:151-158.

20. Hall CS, van de Castle RL. The Content Analysis of Dreams (Century Psychology Series). New York: Appleton-Century-Crofts; 1966.

21. Park KA. Women and development: the case of South Korea. Comp Polit 1993;25:127-145.

22. Kim SH. Recent divorce trend and policy for the divorce in Korea. Minjok Yeonku 2011;45:65-91.

23. Cotton J. From authoritarianism to democracy in South Korea. Polit Stud 1989;37:244-259.

24. Saxer CJ. From Transition to Power Alternation: Democracy in South Korea, 1987-1997 (East Asia: History, Politics, Sociology, Culture). London: Routledge; 2002.

25. Robinson RE. Korea’s Twentieth-Century Odyssey. Honolulu, Hawaii: University of Hawaii Press; 2007.

26. Skodlar B, Demovsek MZ, Kocmur M. Psychopathology of schizophrenia in Ljubljana (Slovenia) from 1881 to 2000: changes in the content of delusions in schizophrenia patients related to various sociopolitical, technical and scientific changes. Int J Soc Psychiatry 2008;54:101-111.

27. Sher L. Sociopolitical event and technical innovations may affect the content of delusions and the course of psychotic disorder. Med Hypotheses 2000;55:507-509.

28. Tateyama M, Asai M, Hashimoto M, Bartels M, Kasper S. Transcultural study of schizophrenic delusions. Tokyo versus Vienna and Tübingen (Germany). Psychopathology 1998;31:59-68.

29. Bhavsar V, Bhugra D. Religious delusions: finding meanings in psychosis. Psychopathology 2008;41:165-172. 